\title{
Use of screener form allows Food and Health Project, a nutrition education intervention, to obtain participants who are from target socio-demographic group
}

\author{
C. Cunningham, S. Kleemann and C. Glennon Slattery \\ Community Nutrition and Dietetic Service, Dublin Mid Leinster, Marlinstown Office Park, Mullingar, Co. Westmeath, \\ Republic of Ireland
}

Individuals living on a low income have poor diets and high mortality levels from diet-related diseases ${ }^{(1)}$. Lower education levels have also been shown to be a predictor of poorer $\operatorname{diet}^{(2)}$. Education level is said to impact on literacy and it has been estimated that an individual's reading comprehension is about 4 years below the grade at which they left school ${ }^{(3)}$. Effective nutritional intervention programmes need to be developed that take cognisance of the social and educational situations in which individuals are living. The Food and Health Project is a peer-led nutrition education programme underway in the Midlands region of Ireland, which is available to disadvantaged groups. In order to enrol in the Food and Health Project groups must ensure that all their members fill in a Food and Health Project screener form. This screener form was developed from one used by Nelson et al. ${ }^{(4)}$. Material deprivation is measured through questions including: receipt of benefits; household composition; employment status; car ownership. Educational profile is gauged through the screener form by including two questions relating to education; specifically achievement of Irish State examinations (the Junior Certificate and/or the Leaving Certificate, or an equivalent).

The purpose of the present study was to determine both the socio-economic and educational profile of participants in the Food and Health Project over a 1-year period to enable the planning and development of programmes that are tailored to the target client group.

An amalgamation of all the results gives an overall profile of the participants in the project. All participants attending nutrition courses in 2007 filled in the Food and Health Project screener forms ( $n$ 486). These forms were collated and then entered into an Excel spreadsheet. The Table shows the socio-economic and educational profile of participants in 2007.

\begin{tabular}{lc}
\hline & \% of participants \\
\hline Deprivation indices & \\
Receiving payment from Health Board or social welfare & 83 \\
Household in receipt of rent allowance & 19 \\
Medical card holder & 88 \\
Household overcrowded & 4 \\
Lone-parent family & 28 \\
No one in the household employed & 56 \\
Member of the household seeking employment & 34 \\
No access to car or van (or car or van >10 years old) & 76 \\
Educational indices & \\
\hline
\end{tabular}

Inititally, this screener form was just used to ensure that the target audience was being reached. However, almagamating the results shows a profile of participants that is useful when developing and enhancing the programmes offered to groups in the region. As well as having cognisance of budgetary constraints the courses developed must be literacy friendly with emphasis on practical aspects. Individuals on lower income are often described as a 'hard to reach' group; however, ensuring that the programme is user-friendly should make attendance at courses a more satisfying experience for the client group.

1. Anderson A (2007) Proc Nutr Soc 66, 25-32.

2. Freisling H, Emladfa I \& Gall I (2006) J Hum Nutr Diet 19, 437-445.

3. Levandowski BA, Sharma P, Lane SD, Webster N, Nestor AM, Cibula DA \& Huntington S (2006) Health Promot Pract 7, 95.

4. Nelson M, Dick K, Holmes B, Thomas R \& Dowler E (2003) Low Income Diet Methods Study: Project for Food Standards Agency. London: King's College London. 